\title{
Long non-coding RNA GASL1 may inhibit the proliferation of glioma cells by inactivating the TGF- $\beta$ signaling pathway
}

\author{
YUHUA HU, BAOHUA JIAO, LINGYOU CHEN, MAN WANG and XINWANG HAN \\ Department of Neurosurgery, The Second Hospital of Hebei Medical University, Shijiazhuang, Hebei 050000, P.R. China
}

Received May 19, 2018; Accepted February 15, 2019

DOI: $10.3892 / \mathrm{ol} .2019 .10273$

\begin{abstract}
Growth-arrest-associated long non-coding RNA (lncRNA) 1 (GASL1) is an lncRNA with a tumor suppression role in osteosarcoma, whereas its involvement in other malignancies is unknown. In the present study, tumor tissues and adjacent healthy tissues were collected from patients with glioma, and blood samples were collected from patients and healthy controls to detect the expression of GASL1. All patients were followed up for 5 years, and the diagnostic and prognostic values for glioma were evaluated by receiver operating characteristic curve analysis and survival curve analysis, respectively. Potential associations between serum GASL1 and clinicopathological data of patients with glioma were investigated using $\chi^{2}$ testing. A GASL1 expression vector and short hairpin RNA targeting GASL1 were transfected into glioma cells and the effects on TGF- $\beta 1$ expression and cell proliferation were investigated by western blotting and Cell Counting Kit-8 assay. Glioma tumor tissue exhibited significantly lower GASL1 expression compared with in adjacent healthy tissue. Serum levels of GASL1 were lower in patients compared with in healthy controls. Serum GASL1 was identified to be a sensitive biomarker for glioma cancer, and a low expression level of GASL1 was associated with a decreased postoperative survival rate. In glioma cell lines with GASL1 overexpression, TGF- $\beta 1$ expression was decreased and proliferation was inhibited. GASL1 knockdown in glioma cell lines led to increased TGF- $\beta 1$ expression and proliferation. TGF- $\beta 1$ treatment had no effect on GASL1 expression, but TGF- $\beta 1$ treatment partially rescued the inhibition of proliferation in cells overexpressing GASL1. Therefore, GASL1 may inhibit tumor growth of glioma by inactivating the TGF- $\beta$ signaling pathway.
\end{abstract}

Correspondence to: Dr Yuhua Hu, Department of Neurosurgery, The Second Hospital of Hebei Medical University, 215 Hepingxi Road, Shijiazhuang, Hebei 050000, P.R. China

E-mail: otnga59@163.com

Key words: glioma, growth-arrest-associated long non-coding RNA 1 , transforming growth factor- $\beta 1$, proliferation

\section{Introduction}

As a type of tumor originating from glial cells of the spine or brain, glioma is one of the most common types of central nervous system tumors, accounting for $\sim 80 \%$ of all malignant brain tumors (1). Glioma tumors arising in different parts of the central nervous system may have different consequences $(2,3)$. Unlike other types of malignancy, gliomas metastasize through the cerebrospinal fluid, but not the blood circulation to cause drop metastases to the spinal cord (4). Following the establishment of metastasis, treatment outcomes and prognosis are markedly poor (4). In spite of the advances in understanding the development of glioma, the pathogenesis of this disease remains unclear (5). Therefore, in-depth investigation of the molecular mechanism of the occurrence of glioma may lead to improved treatment and prevention.

Genetic factors serve central roles in the pathogenesis of glioma. Certain genetic diseases, including tuberous sclerosis complex and neurofibromatosis type 1 and 2 are associated with the occurrence of glioma (6). Transforming growth factor $\beta$ (TGF- $\beta$ ) signaling is considered to be a central factor in glioma development owing to its role in regulating cancer cell proliferation, migration and invasion $(7,8)$. TGF- $\beta$ inhibits tumor growth at early stages of tumor development, and promotes tumor metastasis at advance stages of the majority of cancer types (9), particularly in glioma $(7,8)$. Long non-coding RNAs (lncRNAs) are a type of non-coding RNA of $>200$ nucleotides in length that serve pivotal roles in the pathogenesis of various types of cancer (10). LncRNAs are also key factors in glioma (11). TGF- $\beta$ signaling has been demonstrated to be regulated by lncRNAs (12). Growth-arrest-associated lncRNA 1 (GASL1) has been identified as a potential tumor suppressor in liver cancer(13). Downregulation of GASL1 was observed in liver cancer, and overexpression of GASL1 inhibited osteosarcoma cell proliferation by inactivating a transcription factor involved in cell cycle progression (13). The involvement of GASL1 in other malignancies remains unknown. Preliminary data obtained from microarray revealed altered expression of GASL1 in glioma tissues compared with in healthy tissues (data not shown). In the present study, the effect of altered GASL1 expression on the proliferation of glioma cells and the role of TGF- $\beta 1$ in this process was investigated.

\section{Materials and methods}

Patient and healthy control samples. A retrospective study was performed to review the clinical data of 62 patients diagnosed 
with glioma in The Second Hospital of Hebei Medical University (Hebei, China). All the patients were diagnosed through pathological examination and treated between March 2010 and March 2013. Patient specimens including tumor tissues, paired adjacent healthy tissues and serum samples were obtained from the specimen library of the hospital. The patients that were included in the study met the following criteria: i) Diagnosis of glioma by pathological examination; ii) first time being treated for glioma; iii) completion of the whole treatment procedure; iv) completion of follow-up; and v) complete clinical data available. The exclusion criteria were as follows: i) Other malignancies diagnosed; ii) other severe diseases diagnosed; iii) prior treatment or transferred to other hospitals during treatment; or iv) mortality due to other causes during follow-up. The 62 patients included 32 males and 30 females, and the ages ranged between 33 and 72 years, with a mean age of 51.2 \pm 5.9 years. Serum samples of 52 healthy volunteers were also obtained from the specimen library of The Second Hospital of Hebei Medical University. The healthy controls received routine physiological examinations during the same period. The controls including 28 males and 24 females, were aged between 31 and 70 years, with a mean age of $50.5 \pm 6.6$ years. No significant differences in age, sex and other basic clinical data were identified between the patient group and control group.

Quantification of TGF- $\beta 1$ by ELISA. Serum TGF- $\beta 1$ was detected using the human TGF- $\beta 1$ ELISA kit (RAB0460; Sigma-Aldrich; Merck KGaA, Darmstadt, Germany). All experiments were performed according to the manufacturer's protocol.

Reverse transcription-quantitative polymerase chain reaction $(R T-q P C R)$. TRIzol ${ }^{\circledR}$ reagent (Invitrogen; Thermo Fisher Scientific, Inc., Waltham, MA, USA) was used to extract total RNA, and tissues were ground in liquid nitrogen before adding TRIzol ${ }^{\circledR}$ to achieve complete cell lysis. Total RNA was transcribed into cDNA using Reverse Transcriptase AMV kit (Sigma-Aldrich; Merck KGaA) and the following temperature conditions: $50^{\circ} \mathrm{C}$ for $20 \mathrm{~min}$ and $80^{\circ} \mathrm{C}$ for $10 \mathrm{~min}$. The qPCR mix was prepared using SYBR ${ }^{\circledR}$ Green Real-Time PCR Master mix (Thermo Fisher Scientific, Inc.). Primers used in PCR were as follows: GASL1 forward, 5'-CTGAGGCCAAAG TTTCCAAC-3' and reverse, 5'-CAGCCTGACTTTCCCTCT TCT-3'; TGF- $\beta 1$ forward, 5'-GGACACCAACTATTGCTT CAG-3' and reverse, 5'-TCCAGGCTCCAAATGTAGG-3'; $\beta$-actin forward, 5'-GACCTCTATGCCAACACAGT-3' and reverse, 5'-AGTACTTGCGCTCAGGAGGA-3'. PCR thermocycling conditions were as follows: $40 \mathrm{sec}$ at $95^{\circ} \mathrm{C}$, followed by 40 cycles of $20 \mathrm{sec}$ at $95^{\circ} \mathrm{C}$ and $40 \mathrm{sec}$ at $57^{\circ} \mathrm{C}$. GASL1 and TGF- $\beta 1$ expression was normalized to $\beta$-actin endogenous control using the $2^{-\Delta \Delta \mathrm{Cq}}$ method (14).

Western blot analysis. Total protein was extracted using radioimmunoprecipitation solution (Thermo Fisher Scientific, Inc.) and bicinchoninic acid assay was performed to determine protein concentration. SDS-PAGE (12\% gel) was performed with $25-\mu \mathrm{g}$ protein/lane. Proteins were transferred onto polyvinylidene difluoride membranes, and blocked with $5 \%$ skimmed milk in TBS with $0.2 \%$ Tween at room temperature for $2 \mathrm{~h}$. Next, membranes were incubated with primary antibodies against TGF- $\beta 1$ (rabbit anti-human; 1:1,500; ab92486; Abcam, Cambridge, MA, USA) and GAPDH (rabbit anti-human; 1:1,200; ab9485; Abcam) at $4^{\circ} \mathrm{C}$ overnight. Subsequently, membranes were incubated with horseradish peroxidase-conjugated anti-rabbit IgG secondary antibody (1:1,000; MBS435036; MyBioSource, Inc., San Diego, CA, USA) for $4 \mathrm{~h}$ at room temperature. Pierce enhanced chemiluminescence western blotting substrate (Thermo Fisher Scientific, Inc.) was added to develop the signal, which was detected using a MYECL ${ }^{\mathrm{TM}}$ Imager (Thermo Fisher Scientific, Inc.). Expression of TGF- $\beta 1$ was normalized to GAPDH endogenous control using ImageJ software (version 1.6; National Institutes of Health, Bethesda, MD, USA).

Cell culture and transfection. The present study included two human glioma cell lines, Hs 683 (ATCC ${ }^{\circledR}$ HTB-138 ${ }^{\mathrm{TM}}$ ) and CCD-25Lu (ATCC ${ }^{\circledR}$ CCL-215 ${ }^{\mathrm{TM}}$ ). The two cell lines were purchased from the American Type Culture Collection (ATCC; Manassas, VA, USA). Cells were cultured with ATCC-formulated Eagle's minimum essential medium (cat. no. 30-2003; ATCC) containing 10\% fetal bovine serum (Sangon Biotech Co., Ltd., Shanghai, China). GASL1 short hairpin (sh)RNA (5'-GACGTGTCAGGACCTTCGT-3') and negative control shRNA were synthesized by Shanghai GenePharma Co., Ltd. (Shanghai, China). PCR was performed to obtain an EcoRI/EcoRI fragment containing full-length GASL1 cDNA (performed by Sangon Biotech Co., Ltd.). The GASL1 cDNA was amplified by PCR using the cDNA generated from RT-PCR as a template. The sequences of the primers were as follows: Forward, 5'-GAATTAGGGTGC GTCACCGGAGCAG-3' and reverse, 5'-AATTCGGTTTTT CTTTCTTAGTTTATTT-3'. The PCR mix was prepared using Phusion ${ }^{\circledR}$ High-Fidelity DNA Polymerase kit (New England BioLabs, Inc., Ipswich, MA, USA). The thermocycling conditions were $30 \mathrm{sec}$ at $98^{\circ} \mathrm{C}$, followed by 40 cycles of $10 \mathrm{sec}$ at $98^{\circ} \mathrm{C}, 10 \mathrm{sec}$ at $55^{\circ} \mathrm{C}$ and $70 \mathrm{sec}$ at $72^{\circ} \mathrm{C}$. This fragment was inserted into pIRSE2-EGFP vector (Clontech Laboratories, Inc., Mountainview, CA, USA) to construct a GASL1 expression vector. Lipofectamine ${ }^{\circledR} 2000$ reagent (cat. no. 11668-019; Invitrogen; Thermo Fisher Scientific, Inc.) was used to transfect $10 \mathrm{nM}$ vector and $50 \mathrm{nM}$ shRNA into $5 \times 10^{5}$ cells. Negative control shRNA and empty pIRSE2-EGFP vector were used as negative controls. Untransfected cells were used as controls. Overexpression and knockdown were confirmed by RT-qPCR, as mentioned before. All subsequent experiments were performed on samples in which expression of GASL1 was $\geq 200 \%$ for overexpression or $\leq 50 \%$ for knockdown at $24 \mathrm{~h}$ after transfections compared with expression in the control group.

Cell proliferation assay. A Cell Counting Kit-8 (CCK-8) assay was performed to evaluate cell proliferation. In cases of TGF- $\beta 1$ treatment, cells were treated with TGF- $\beta 1$ (Sigma-Aldrich; Merck $\mathrm{KGaA}$ ) at a dose of $10 \mathrm{ng} / \mathrm{ml}$ for $12 \mathrm{~h}$ at $37^{\circ} \mathrm{C}$ before use. Hs 683 and CCD-25Lu cells were collected during exponential phase to make cell suspensions with a density of $4 \times 10^{4}$ cells $/ \mathrm{ml}$. Of this, $4 \times 10^{3}$ cells were added to each well of a 96-well plate. Cells were cultured for 24, 48, 72 and $96 \mathrm{~h}$ in an incubator at $37^{\circ} \mathrm{C}$ with $5 \% \mathrm{CO}_{2}$, at which point $10 \mu \mathrm{l}$ CCK-8 solution (Sigma-Aldrich; Merck KGaA) was added. 
Table I. Serum GASL1 level and clinicopathological data of 62 patients with glioma.

\begin{tabular}{|c|c|c|c|c|c|}
\hline Characteristics & Cases, $\mathrm{n}$ & High GASL1, n & Low GASL1, n & $\chi^{2}$ & P-value \\
\hline Age, years & & & & 0.58 & 0.45 \\
\hline$>50$ & 29 & 13 & 16 & & \\
\hline$<50$ & 33 & 18 & 15 & & \\
\hline Sex & & & & 1.03 & 0.31 \\
\hline Male & 32 & 14 & 18 & & \\
\hline Female & 30 & 17 & 13 & & \\
\hline Alcohol consumption & & & & 0.28 & 0.60 \\
\hline Yes & 22 & 12 & 10 & & \\
\hline No & 40 & 19 & 21 & & \\
\hline Smoking & & & & 0.62 & 0.43 \\
\hline Yes & 23 & 10 & 13 & & \\
\hline No & 39 & 21 & 18 & & \\
\hline Primary tumor diameter, $\mathrm{cm}$ & & & & 6.51 & 0.01 \\
\hline$>2$ & 28 & 9 & 19 & & \\
\hline$<2$ & 34 & 22 & 12 & & \\
\hline Tumor distant metastasis & & & & 0.60 & 0.44 \\
\hline Yes & 25 & 11 & 14 & & \\
\hline No & 37 & 20 & 17 & & \\
\hline
\end{tabular}

GASL1, growth-arrest-associated long non-coding RNA 1.

Following culture for a further $4 \mathrm{~h}$, optical density values were determined at $450 \mathrm{~nm}$ using a Fisherbrand ${ }^{\mathrm{TM}} \operatorname{accuSkan}^{\mathrm{TM}}$ GO UV/Vis microplate spectrophotometer (Thermo Fisher Scientific, Inc.) to assess cell proliferation. OD value of control group was set to $100 \%$, and all other groups and other time points were normalized to this value.

Statistical analysis. Statistical analysis was performed using SPSS (version 19.0; IBM Corp., Armonk, NY, USA). GASL1 and TGF- $\beta 1$ expression levels were recorded as the mean \pm standard deviation, and comparisons between two groups and among multiple groups were performed by Student's t-test and one-way analysis of variance (ANOVA) followed by Tukey's post hoc test, respectively. The $\chi^{2}$ test was performed to analyze the association between GASL1 expression and clinical data of patients with glioma. Pearson's correlation coefficient was used to analyze TGF- $\beta 1$ and GASL1 expression for potential correlations. Receiver operating characteristic (ROC) curve analysis was performed to evaluate the diagnostic value of serum GASL1 for glioma with patients as true positive cases and controls as true negative cases. The 62 patients with glioma were divided into high and low level expression groups $(n=31)$ according to the median serum level of GASL1. Kaplan-Meier method was used to plot survival curves and the two groups were compared using a log-rank test. $\mathrm{P}<0.05$ was considered to indicate a statistically significant difference.

\section{Results}

Expression of GASL1 in tumor tissues and paired normal tissues of 62 patients with glioma. GASL1 expression in tumor tissues and paired normal tissues of 62 patients with glioma was detected using RT-qPCR. The results demonstrated that a majority of patients with glioma $(56 / 62,90.3 \%)$ had significantly decreased expression of GASL1 in tumor tissues compared with expression in paired adjacent healthy tissues $(\mathrm{P}<0.05$; Fig. 1), indicating that downregulation of GASL1 may be involved in the pathogenesis of glioma.

Comparison of serum level of GASL1 in patients with glioma and in healthy controls, and analysis of the diagnostic value of serum GASL1. Serum levels of GASL1 in patients with glioma and in healthy controls were also determined using RT-qPCR. As presented in Fig. 2A, the serum level of GASL1 was significantly lower in patients with glioma compared with that in healthy controls $(\mathrm{P}<0.05)$. Receiver operating characteristic (ROC) curve analysis was performed to evaluate the diagnostic value of serum GASL1 for glioma. As presented in Fig. 2B, the area under the curve was 0.8838 , with standard error of 0.03429 and $95 \%$ confidence interval of 0.8166 to 0.9511 . Therefore, serum GASL1 may serve as a potential diagnostic biomarker for glioma.

Prognostic value of serum GASL1 for glioma. The 62 patients with glioma were divided into high and low level expression groups $(n=31)$ according to the median serum level of GASL1. All patients were followed up for 5 years or until their mortality to determine the survival rate. The Kaplan-Meier method was used to plot survival curves and the two groups were compared using a log-rank test. As presented in Fig. 3, the overall survival rate of patients with a low serum level of GASL1 was significantly worse compared with that of patients with a high serum level of GASL1. 


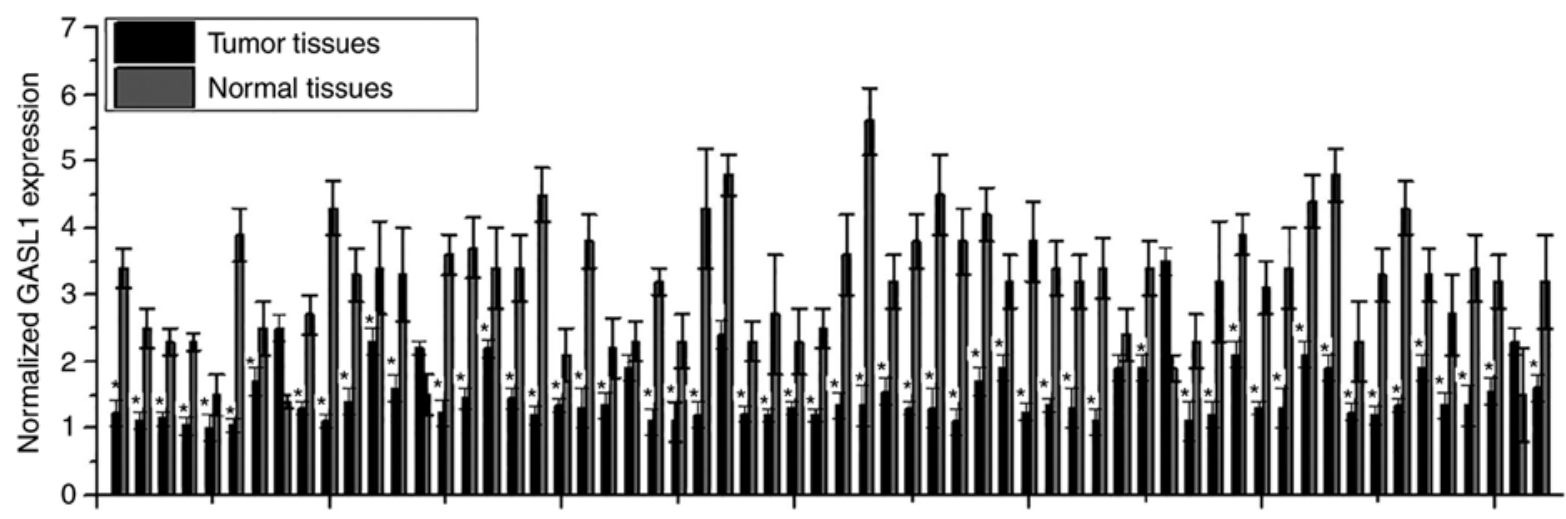

Patients with glioma $(n=62)$

Figure 1. Expression of GASL1 in tumor tissues and paired normal tissues from 62 patients with glioma. "P<0.05 vs. normal tissues. GASL1, Growth-arrest-associated long non-coding RNA 1.

A

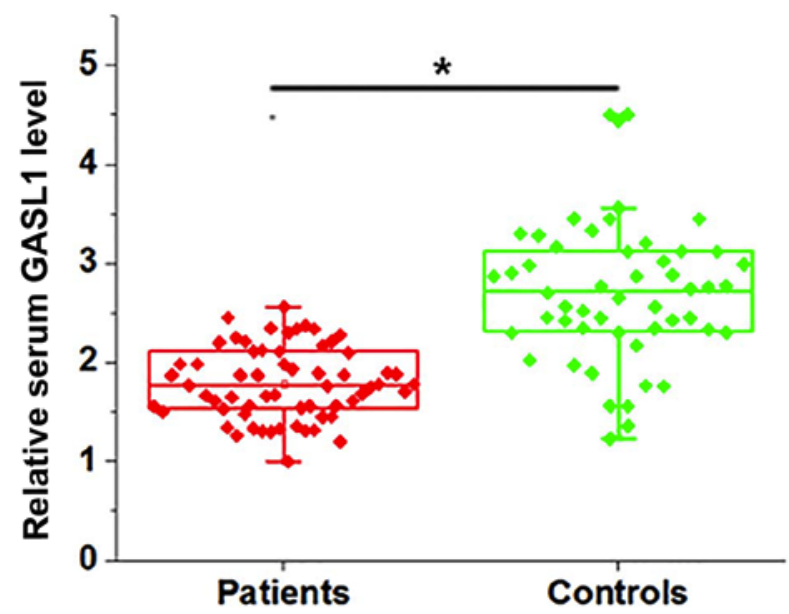

B

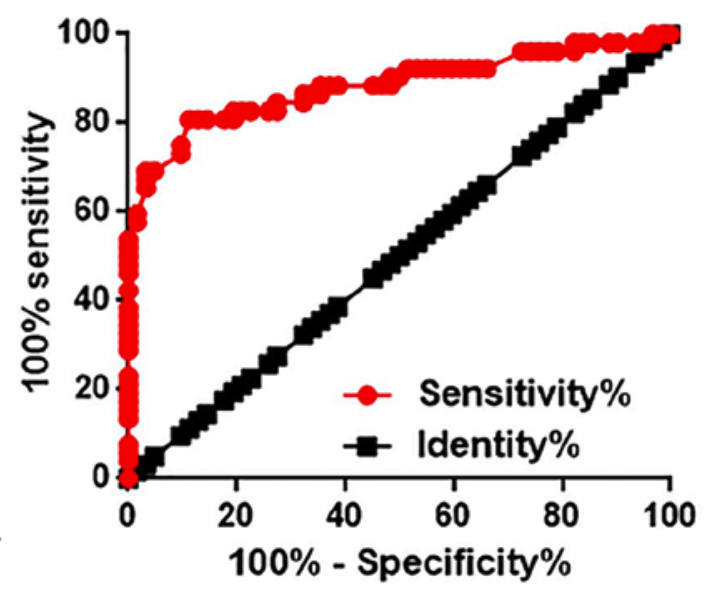

Figure 2. Serum GASL1 levels in patients with glioma and in healthy controls. (A) Comparison of serum level of GASL1 in patients with glioma and in healthy controls; (B) ROC curve analysis of the diagnostic value of serum GASL1 for glioma. " $\mathrm{P}<0.05$. GASL1, Growth-arrest-associated long non-coding RNA 1.

Association between serum levels of GASL1 and patients' clinicopathological data. Potential associations between serum levels of GASL1 and patients' clinicopathological data were analyzed using a $\chi^{2}$ test. As presented in Table I, no significant correlations were identified between serum levels of GASL1 and patients' age, sex, smoking habit, drinking habit and existence of distant tumor metastasis. In contrast, there was a significant inverse correlation between levels of serum GASL1 and tumor size.

Interactions between GASL1 and TGF- $\beta 1$ in glioma cells. The data in Table I indicate that GASL1 may be involved in the growth of glioma. It has been reported that activation of TGF- $\beta$ promotes growth of glioma (8). In the present study, Pearson's correlation analysis revealed a significant negative correlation between serum GASL1 and TGF- $\beta 1$ in patients with glioma (Fig. 4A), but not in healthy controls (Fig. 4B). In addition, the effects of GASL1 overexpression and knockdown on the expression of TGF- $\beta 1$ in glioma cell lines were examined. GASL1 overexpression and shRNA-mediated knockdown of GASL1 were successfully achieved in two glioma cell lines, Hs 683 (Fig. 5A) and CCD-25Lu (Fig. 5B). GASL1 overexpression

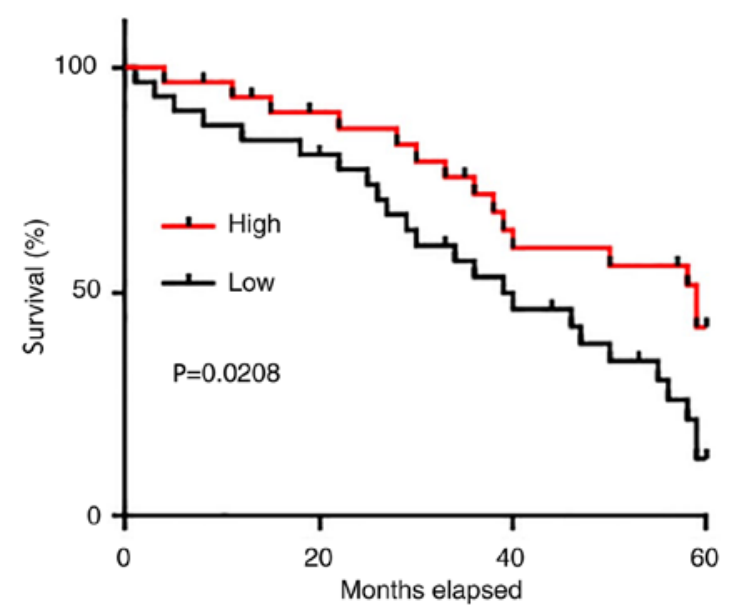

Figure 3. Survival analysis of patients with high and low serum levels of GASL1. GASL1, Growth-arrest-associated long non-coding RNA 1.

significantly inhibited and shRNA silencing significantly promoted the expression TGF- $\beta 1$ in cells of glioma cell lines Hs 683 (Fig. 5C) and CCD-25Lu (Fig. 5D). However, treatment 

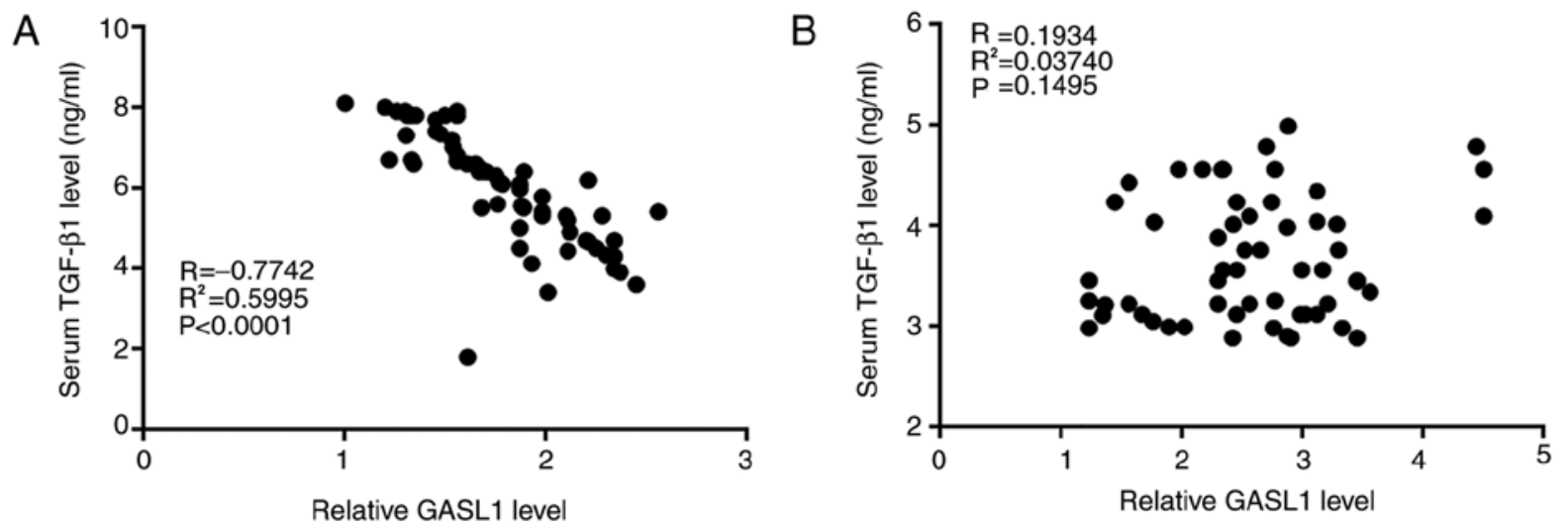

Figure 4. Correlation between serum GASL1 and TGF- $\beta 1$ in (A) patients with glioma and (B) healthy controls. Pearson's correlation analysis revealed a significant negative correlation between serum GASL1 and TGF- $\beta 1$ in patients with glioma. GASL1, Growth-arrest-associated long non-coding RNA 1; TGF- $\beta 1$, transforming growth factor- $\beta 1$.

A
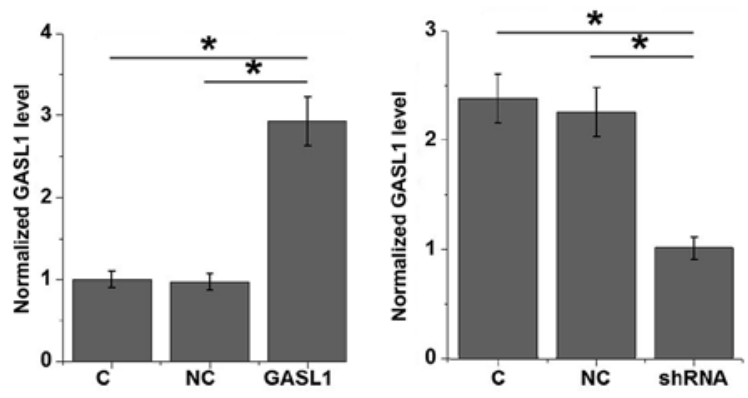

C
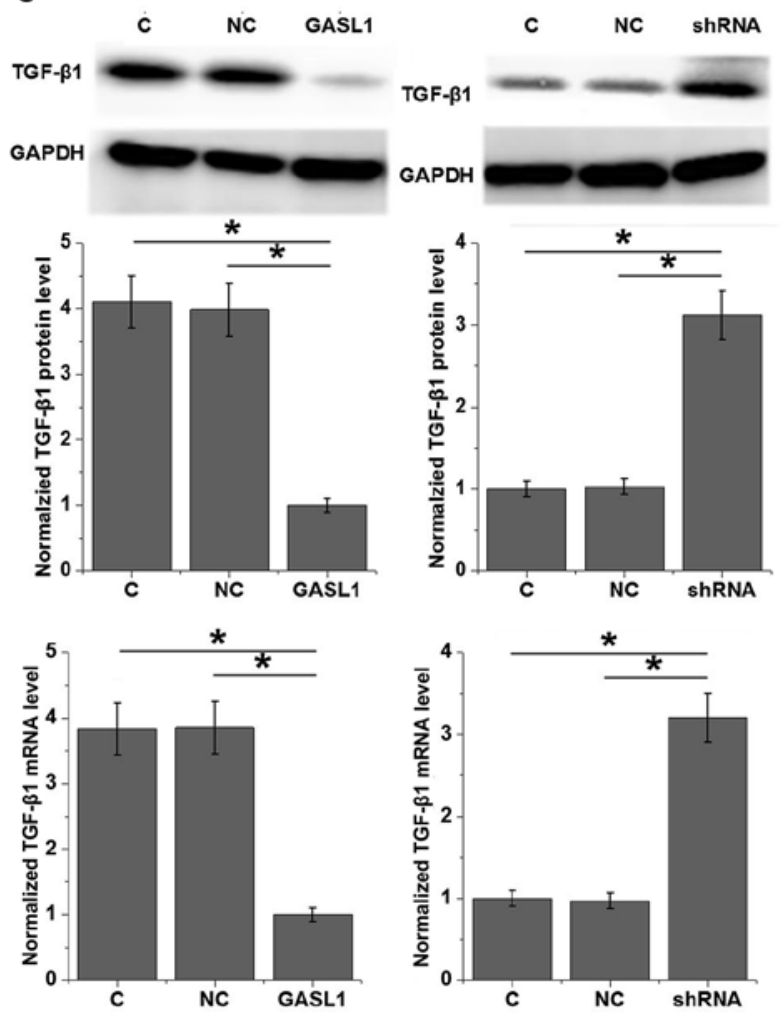

B
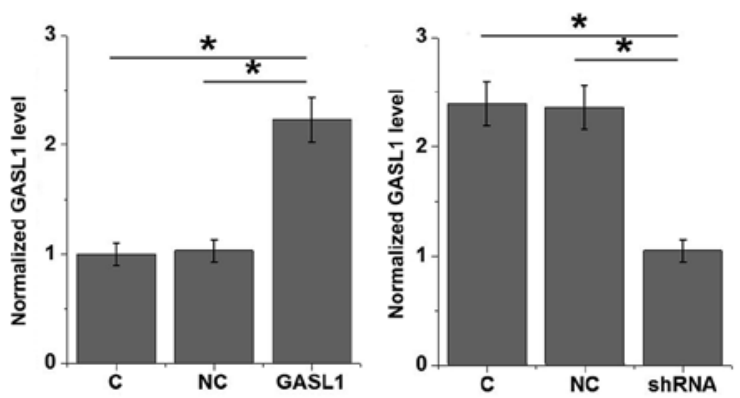

D
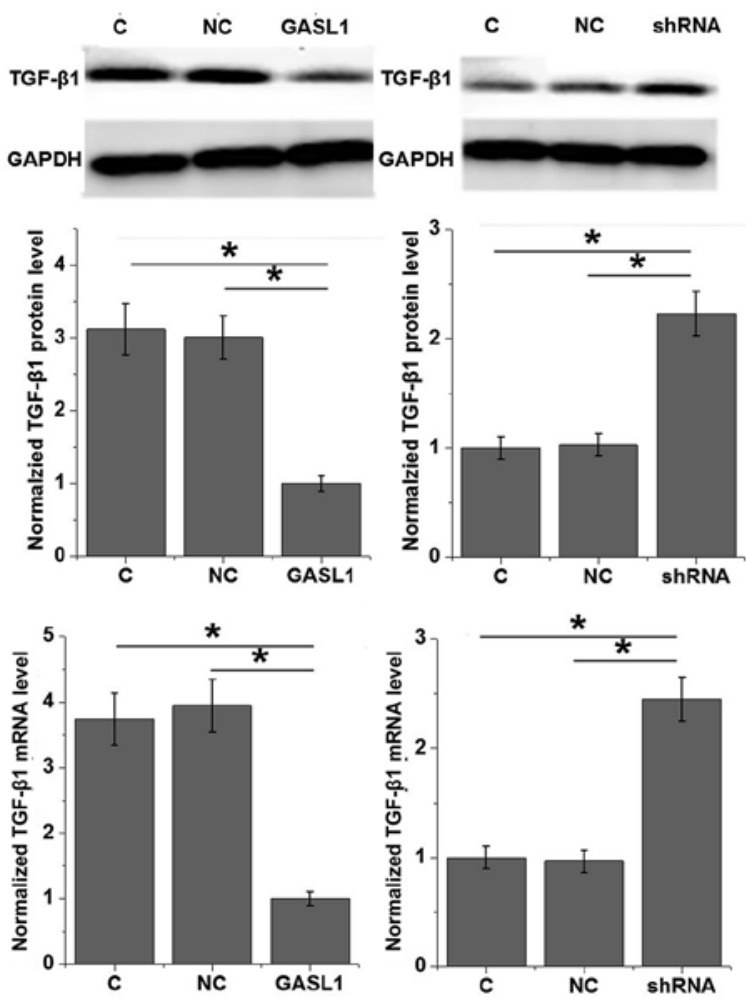

Figure 5. Interaction between GASL1 and TGF- $\beta 1$ in glioma cell lines. Data were analyzed by one-way analysis of variance with a Tukey's post-hoc test. GASL1 overexpression and shRNA-mediated knockdown in (A) Hs 683 and (B) CCD-25Lu cells. TGF- $\beta 1$ mRNA and protein expression in (C) Hs 683 and (D) CCD-25Lu cells with GASL1 overexpressed or knocked down. "P<0.05. GASL1, Growth-arrest-associated long non-coding RNA 1; TGF- $\beta 1$, transforming growth factor- $\beta 1$; shRNA, short hairpin RNA; $\mathrm{C}$, control; NC, negative control. 

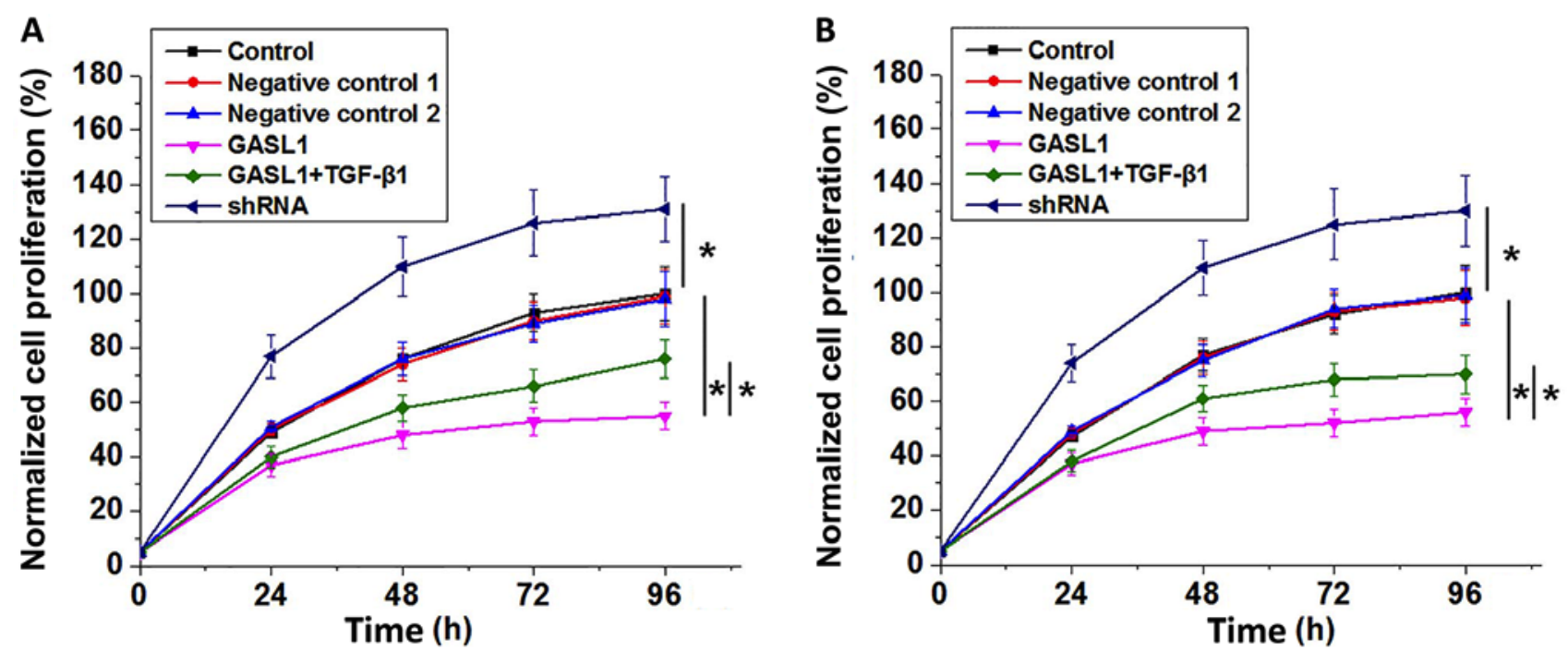

Figure 6. Effects of GASL1 overexpression and knockdown and TGF- $\beta 1$ treatment on proliferation of (A) Hs 683 and (B) CCD-25Lu glioma cells. One-way analysis of variance with a Tukey's post-hoc test was performed to compare cell proliferation data among different cell transfection groups. It was found that GASL1 overexpression significantly inhibited and GASL1 significantly promoted the proliferation of human glioma cells. In addition, treatment with TGF- $\beta 1$ at a dose of $10 \mathrm{ng} / \mathrm{ml}$ significantly decreased the inhibitory effect of GASL1 overexpression on cell proliferation in the two cell lines. "P $<0.05$. Growth-arrest-associated long non-coding RNA 1 ; TGF- $\beta 1$, transforming growth factor- $\beta 1$; shRNA, short hairpin RNA.

with TGF- $\beta 1$ (5, 10 and $50 \mathrm{ng} / \mathrm{ml}$; Sigma-Aldrich) for $12 \mathrm{~h}$ had no significant effect on GASL1 expression (data not shown). Therefore, GASL1 may be an upstream inhibitor of TGF- $\beta 1$.

Effects of GASL1 overexpression and knockdown and TGF- $\beta 1$ treatment on cell proliferation. As presented in Fig. 6, analysis of cell proliferation data by one-way ANOVA with a post-hoc Tukey's test showed that GASL1 overexpression significantly inhibited and GASL1 significantly promoted the proliferation of two human glioma cell lines, Hs 683 (Fig. 6A) and CCD-25Lu (Fig. 6B). In addition, treatment with TGF- $\beta 1$ at a dose of $10 \mathrm{ng} / \mathrm{ml}$ significantly decreased the inhibitory effect of GASL1 overexpression on cell proliferation in the two cell lines.

\section{Discussion}

GASL1 is an lncRNA that was identified as a tumor suppressor gene in osteosarcoma (12). The key result of the present study is that GASL1 may also serve a role as a tumor suppressor gene in glioma by inhibiting cancer cell proliferation. The action of GASL1 in glioma may be achieved through the downregulation of TGF- $\beta 1$. In addition, the results of the present study also revealed that circulating GASL1 in the serum of patients with glioma may have diagnostic and prognostic value for glioma.

Previous studies in the last several decades have indicated that the occurrence, development and progression of glioma are accompanied by changes in expression patterns of a large set of genes, and certain genes may act as tumor suppressors or oncogenes (6). LncRNAs are potentially key factors in different types of malignancy including glioma $(9,10)$. Expression of the lncRNA ADAMTS9 antisense RNA 2 (ADAMTS9-AS2) is significantly decreased in glioma tissues compared with that in paired adjacent normal cells, and downregulation of ADAMTS9-AS2 increased the migration of glioma cells (15). In contrast, H19 is an oncogenic IncRNA with increased expression in glioma (16). A previous study reported that GASL1 is downregulated in liver cancer (13), revealing its role as a potential tumor suppressor gene in this disease. In the present study, GASL1 in tumor tissues was decreased compared with that in paired adjacent healthy tissues, indicating that GASL1 may also be a tumor suppressor gene in glioma.

Circulating biomarkers are widely used in the diagnosis and prognosis of different types of cancer (17). The main challenge in the treatment of glioma is the presence of distant tumor metastasis, and early and accurate diagnosis remains the key factor in influencing the survival rate of patients (18). In the present study, levels of circulating GASL1 in serum of patients with glioma were identified to be significantly lower compared with in healthy controls. ROC curve analysis indicated that decreased serum GASL1 may be a useful biomarker to distinguish patients with glioma from healthy controls. In addition, survival curve comparison also indicated that low serum levels of GASL1 were associated with a poor postoperative survival rate. Therefore, circulating GASL1 may serve as a potential diagnostic and prognostic biomarker for glioma. However, GASL1 is a novel lncRNA lacking known expression patterns in other diseases. Therefore, a combination of multiple biomarkers should be used to improve the accuracy of diagnosis and prognosis.

The results of the present study also demonstrated that serum GASL1 is significantly associated with tumor size, but not with tumor metastasis. In vitro investigation revealed that GASL1 can inhibit the proliferation of glioma cells. TGF- $\beta$ signaling serves a central role in the pathogenesis of various types of cancer $(9,19,20)$. As a double-edged sword in cancer biology, TGF- $\beta$ signaling induces cancer cell migration and invasion, but also exerts anti-proliferative effects (9). However, it is generally considered that TGF- $\beta$ signaling accelerates the proliferation rate of glioma cells (8). In the present study, GASL1 was identified as a potential upstream inhibitor of 
TGF- $\beta 1$. In addition, TGF- $\beta 1$ treatment significantly decreased the inhibitory effects of GASL1 overexpression on glioma cell proliferation. This partial rescue of cell proliferation by TGF- $\beta$ has been reported previously (21). GASL1 may inhibit the growth of glioma by downregulating TGF- $\beta 1$ expression. However, the effect of GASL1 on the regulation of TGF- $\beta 1$ expression may not be direct, as no significant correlation was identified between serum GASL1 and TGF- $\beta 1$ in healthy controls. Therefore, there may be glioma-specific factors that mediate the association between GASL1 and TGF- $\beta 1$.

The present study identified a negative correlation between GASL1 and TGF- $\beta 1$ in serum samples of patients with glioma, but not in those of healthy controls. However, the potential correlation between expression of GASL1 and TGF- $\beta 1$ in tumor tissues of patients with glioma was not investigated owing to a lack of tumor tissues. Future studies are required to perform this analysis.

In conclusion, GASL1 expression was significantly decreased in glioma tissue compared with that in normal tissue. Serum GASL1 may serve as a potential diagnostic and prognostic biomarker for glioma. GASL1 overexpression inhibited glioma cell proliferation and downregulated TGF- $\beta 1$ expression, but TGF- $\beta 1$ treatment decreased the effect of GASL1 overexpression on proliferation. Therefore, lncRNA GASL1 may inhibit growth of glioma by inactivating the TGF- $\beta$ signaling pathway.

\section{Acknowledgements}

Not applicable.

\section{Funding}

No funding was received.

\section{Availability of data and materials}

The datasets used and/or analyzed during the current study are available from the corresponding author on reasonable request.

\section{Authors' contributions}

$\mathrm{YH}, \mathrm{BJ}, \mathrm{LC}, \mathrm{MW}$ and $\mathrm{XH}$ were responsible for the conception and design of the study. YH and BJ performed the experiments. YH, LC and MW analyzed and interpreted the data. YH drafted the article. BJ, LC, MW and $\mathrm{XH}$ were responsible for the revision of the manuscript.

\section{Ethics approval and consent to participate}

The protocol of the present study was approved by the Ethics Review Committee of The Second Hospital of Hebei Medical University (Hebei, China).

\section{Patient consent for publication}

Not applicable.

\section{Competing interests}

The authors declare that they have no competing interests.

\section{References}

1. Goodenberger ML and Jenkins RB: Genetics of adult glioma. Cancer Genet Cytogenet 205: 613-621, 2012.

2. Omuro A and DeAngelis LM: Glioblastoma and other malignant gliomas: A clinical review. JAMA 310: 1842-1850, 2013.

3. Mishra MV, Andrews DW, Glass J, Evans JJ, Dicker AP, Shen X and Lawrence YR: Characterization and outcomes of optic nerve gliomas: A population-based analysis. J Neurooncol 107: 591-597, 2012.

4. Stark AM, van de Bergh J, Hedderich J, Mehdorn HM and Nabavi A: Glioblastoma: Clinical characteristics, prognostic factors and survival in 492 patients. Clin Neurol Neurosurg 114: 840-845, 2012.

5. Ichimura K: Molecular pathogenesis of IDH mutations in gliomas. Brain Tumor Pathol 29: 131-139, 2012.

6. Radner H, El-Shabrawi Y, Eibl RH, Brüstle O, Kenner L, Kleihues P and Wiestler OD: Tumor induction by ras and myc oncogenes in fetal and neonatal brain: Modulating effects of developmental stage and retroviral dose. Acta Neuropathol 86: 456-465, 1993.

7. Kaminska B, Kocyk M and Kijewska M: TGF-beta signaling and its role in glioma pathogenesis. Adv Exp Med Biol 986: 171-187, 2013.

8. Bruna A, Darken RS, Rojo F, Ocaña A, Peñuelas S, Arias A, Paris R, Tortosa A, Mora J, Baselga J and Seoane J: High TGF-beta Smad activity confers poor prognosis in glioma patients and promotes cell proliferation depending on the methylation of the PDGF-B gene. Cancer Cell 11: 147-160, 2007.

9. Akhurst RJ and Derynck R: TGF-beta signaling in cancer-a double-edged sword. Trends Cell Biol 11: S44-S51, 2001.

10. Yang G, Lu X and Yuan L: LncRNA: A link between RNA and cancer. Biochim Biophys Acta 1839: 1097-1109, 2014.

11. Kiang KM, Zhang XQ and Leung GK: Long non-coding RNAs: The key players in glioma pathogenesis. Cancers (Basel) 7: 1406-1424, 2015

12. Yuan JH, Yang F, Wang F, Ma JZ, Guo YJ, Tao QF, Liu F, Pan W, Wang TT, Zhou CC, et al: A long noncoding RNA activated by TGF- $\beta$ promotes the invasion-metastasis cascade in hepatocellular carcinoma. Cancer Cell 25: 666-681, 2014.

13. Gasri-Plotnitsky L, Ovadia A, Shamalov K, Nizri-Megnaji T, Meir S, Zurer I, Cohen CJ and Ginsberg D: A novel lncRNA, GASL1, inhibits cell proliferation and restricts E2F1 activity. Oncotarget 8: 23775-23786, 2017.

14. Livak KJ and Schmittgen TD: Analysis of relative gene expression data using real-time quantitative PCR and the 2(-Delta Delta C(T)) method. Methods 25: 402-408, 2001.

15. Yao J, Zhou B, Zhang J, Geng P, Liu K, Zhu Y and Zhu W: A new tumor suppressor LncRNA ADAMTS9-AS2 is regulated by DNMT1 and inhibits migration of glioma cells. Tumour Biol 35: 7935-7944, 2014.

16. Shi Y, Wang Y, Luan W, Wang P, Tao T, Zhang J, Qian J, Liu N and You Y: Long non-coding RNA H19 promotes glioma cell invasion by deriving miR-675. PLoS One 9: e86295, 2014.

17. Pritchard CC, Kroh E, Wood B, Arroyo JD, Dougherty KJ, Miyaji MM, Tait JF and Tewari M: Blood cell origin of circulating microRNAs: A cautionary note for cancer biomarker studies. Cancer Prev Res (Phila) 5: 492-497, 2012.

18. Lei B, Xiang W, Yu M, Yu L and Qi S: Case report glioma progress and extracranial systemic multiple metastasis: A case report. Int J Clin Exp Med 9: 16883-16886, 2016.

19. Derynck R, Akhurst RJ and Balmain A: TGF-beta signaling in tumor suppression and cancer progression. Nat Genet 29: 117-129, 2001.

20. Bellam $\mathrm{N}$ and Pasche B: TGF- $\beta$ signaling alterations and colon cancer. Cancer Treat Res 155: 85-103, 2010.

21. Li Z, Dong M, Fan D, Hou P, Li H, Liu L, Lin C, Liu J, Su L, Wu L, et al: LncRNA ANCR down-regulation promotes TGF- $\beta$-induced EMT and metastasis in breast cancer. Oncotarget 8 : 67329-67343, 2017. 